\title{
Histomorphometric Analysis of Osseointegrated Grade V Titanium Mini Transitional Implants inEdentulous Mandible by Backscattered Scanning Electron Microscopy (BS-SEM)
}

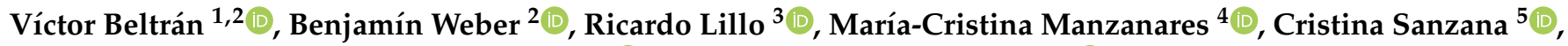 \\ Nicolás Fuentes ${ }^{3}$, Pablo Acuña-Mardones ${ }^{1}$ (D) and Ivan Valdivia-Gandur ${ }^{6,7, *(\mathbb{B})}$ \\ 1 Clinical Investigation and Dental Innovation Center (CIDIC), Dental School and Center for Translational \\ Medicine (CEMT-BIOREN), Universidad de La Frontera, Temuco 4811230, Chile; \\ victor.beltran@ufrontera.cl (V.B.); pablo.acuna@ufrontera.cl (P.A.-M.) \\ 2 Postgraduate Program in Oral Rehabilitation, Department of Integral Adults Dentistry, Dental School, \\ Universidad de La Frontera, Temuco 4811230, Chile; benjamin.weber@ufrontera.cl \\ 3 Postgraduate Program in Oral Implantology, Dental School, Universidad Mayor, Santiago 7510041, Chile; \\ rlilloe@gmail.com (R.L.); nicolas.fuentes.f@gmail.com (N.F.) \\ 4 Muscular and Skeletal Pathology Research, Human Anatomy and Embryology Unit, Universitat de \\ Barcelona, 08193 Barcelona, Spain; mcmanzanares@ub.edu \\ 5 Institute of Dental Sciences and Postgraduate Program in Oral Implantology, Facultad de Odontología, \\ Universidad de Chile, Santiago 8380544, Chile; csanzana@ug.uchile.cl \\ 6 Dentistry Department, University of Antofagasta, Avenida Angamos 601, Antofagasta 1270300, Chile \\ 7 Biomedical Department, University of Antofagasta, Avenida Angamos 601, Antofagasta 1270300, Chile \\ * Correspondence: ivan.valdivia@uantof.cl; Tel.: +56-55-637018
}

\section{check for} updates

Citation: Beltrán, V.; Weber, B.; Lillo, R.; Manzanares, M.; Sanzana, C.; Fuentes, N.; Acuña-Mardones, P.; Valdivia-Gandur, I. Histomorphometric Analysis of Osseointegrated Grade V Titanium Mini Transitional Implants in Edentulous Mandible by Backscattered Scanning Electron Microscopy (BS-SEM). Metals 2021, 11， 2. https://dx.doi.org/10.3390/met1101 0002

Received: 30 October 2020

Accepted: 27 November 2020

Published: 22 December 2020

Publisher's Note: MDPI stays neutral with regard to jurisdictional claims in published maps and institutional affiliations.

Copyright: (c) 2020 by the authors. Licensee MDPI, Basel, Switzerland. This article is an open access article distributed under the terms and conditions of the Creative Commons Attribution (CC BY) license (https: / / creativecommons.org/ licenses/by/4.0/).
Abstract: The purpose of this study is to assess the use of grade $\mathrm{V}$ titanium mini transitional implants (MTIs) immediately loaded by a temporary overdenture. For this, a histomorphometric analysis of the bone area fraction occupancy (BAFO) was performed by backscattered scanning electron microscopy (BS-SEM). Four female patients were submitted to surgery in which two MTIs were installed and immediately loaded with a temporary acrylic prosthesis. During the same surgery, two regular diameter implants were placed inside the bone and maintained without mechanical load. After 8 months, the MTIs were extracted using a trephine and processed for ultrastructural bone analysis by BS-SEM, and the regular-diameter implants were loaded with an overdenture device. A total of 243 BAFOs of MTIs were analyzed, of which 94 were mainly filled with cortical bone, while 149 were mainly filled with trabecular bone. Bone tissue analysis considering the total BAFOs with calcified tissues showed $72.13 \%$ lamellar bone, $26.04 \%$ woven bone, and $1.82 \%$ chondroid bone without significant differences between the samples. This study revealed that grade $\mathrm{V}$ titanium used in immediately loaded MTI was successfully osseointegrated by a mature and vascularized bone tissue as assessed from the BAFO.

Keywords: grade V titanium; mini transitional implants; narrow diameter implant; backscattered electrons

\section{Introduction}

One alternative to addressing the overly narrow residual ridges of the mandible is the use of dental mini implants (with a diameter below $3 \mathrm{~mm}$ ) [1], which represent an important therapeutic option in cases in which reconstructive surgeries are contraindicated or as an alternative to other surgical procedures that present greater morbidity [2]. For these cases, the use of alloys with improved mechanical properties is desired for use in dental implants [3]. In this context, grade V titanium mini transitional implants (MTIs) can be a better alternative in these clinical cases because of their high mechanical resistance. These procedures allow the clinician to perform restoration and maintenance work in the vertical dimension with the use of mini implants in conjunction with implant surgical therapy, 
which is considered to be an effective method to provide the patient with an immediate and comfortable transitional appliance [4].

Grade V titanium alloy is widely used to fabricate medical and dental implants due to its superior physical, mechanical $[5,6]$, and biological properties compared to other available biomedical metals and alloys. Specifically, its resistance to corrosion, excellent biocompatibility, lightweight, and superior tribological properties make this material far superior to other metals and alloys and highly useful for dental application $[7,8]$. Moreover, various authors have demonstrated its osseointegration [9-11]. Complications related to biocompatibility [12] or toxicity [13] of titanium alloys have been reported, including a mildly increased inflammatory response in direct contact to skeletal muscle [14]. Still, the evidence that includes human biopsies is scant.

Ultrastructural bone analysis has been performed by backscattered scanning electron microscopy (BS-SEM). This is an effective technique for studying the osseointegration of dental implants [15]; however, there is scarce evidence regarding the osseointegration of grade $\mathrm{V}$ titanium dental implants in humans when considering transitional implants immediately loaded and associated with overdenture. The purpose of this study is to assess the use of grade V titanium MTIs as immediately loaded implants for temporary overdenture, performing the analysis of the bone tissue close to the implant surface in human biopsies.

\section{Materials and Methods}

\subsection{Patients and Surgical Procedure}

The study was approved by the Ethics Committee of the University Mayor, Chile (Protocol N²46/006). Four female patients (60-68 years of age, health compatible with treatment) who were non-smokers, users of acrylic removable dentures over the completely edentulous mandible, and with horizontal atrophy of the anterior area were selected for treatment using an overdenture which was fixed temporally by MTIs. Prior to implant placement, all patients signed for informed consent regarding description of the placement and removal of the MTIs. The surgical protocol involved the simultaneous placement of submerged regular implants (4.0 mm Titamax EX or $4.3 \mathrm{~mm}$ Alvim Morse Taper) and MTIs for immediate loading in the edentulous lower mandible. The submerged regular implants that were not loaded were maintained and controlled for their osseointegration in the traditional way (6-8 months to implant osseointegration).

Each patient received two MTIs (2.9 mm in diameter and $12 \mathrm{~mm}$ long, Facility Neodent with Neoporos, Curitiba, Brazil) that were placed in the canine mandible region with O-rings for fixation of the overdentures. The MTIs were placed with a mandatory insertion torque of at least $35 \mathrm{Ncm}$ and maximum $45 \mathrm{Ncm}$ measured by a drill unit (W\&H Implant Med). The suture was performed using polyglactin 9104.0 (Vicryl ${ }^{\circledR}$, Ethicon Endo-Surgery Inc., Greensboro, NC, USA). Immediately after the surgery, MTIs were loaded with a removable overdenture following the loading protocol under the Schnitman concept [16]. Then, patients were controlled at 2, 7, 30, 60, and 90 days.

After 8 months, the MTIs were extracted with a trephine bur of $3.5 \mathrm{~mm}$ in diameter, and the samples were conditioned for histomorphometric analysis by BS-SEM (Figure 1). 


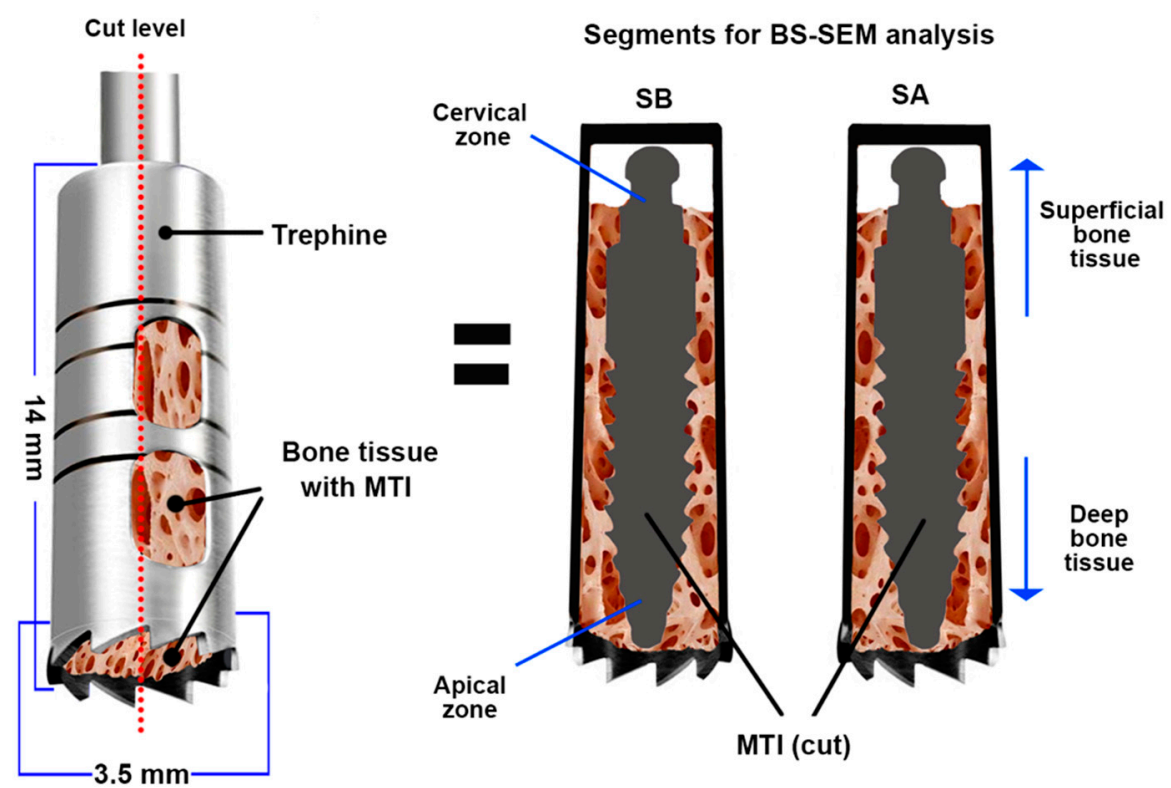

Figure 1. Bone sample with mini transitional implants (MTIs) obtained by trephine. A cut was made to obtain two samples (SA and SB) for backscattered scanning electron microscopy (BS-SEM) analysis. MTI = mini transitional implant; SA and SB = Segments A and B obtained after the cut.

\subsection{Histomorphometric Analysis of Samples by BS-SEM}

The MTIs were surgically removed using a trephine bur (implant plus its bone segment, Figure 1). They were subsequently fixed in $10 \%$ neutral buffered formaldehyde for $48 \mathrm{~h}$. Later, the bone segments were prepared for their inclusion in light-curing resin (Technovit ${ }^{\circledR}$ ). Posteriorly, the included samples were cut following the central longitudinal axis of the implant (Figure 1) using an Exact ${ }^{\circledR}$ diamond band saw $(0.2 \mathrm{~mm}$ thick) and treated for BS-SEM analysis following the procedure described in the literature $[17,18]$.

During BS-SEM analysis, several microphotographs were obtained $(50 \times$ to $150 \times)$. The area of tissue between two threads of the implant surface was established as a study unit (Figure 2), referred to as the "bone area fraction occupancy" (BAFO). The following parameters were analyzed in the BAFOs:

1. Bone tissue classification present in the BAFO considering trabecular or cortical bone. The classification was determined considering the predominant form of bone present.

2. Bone to implant contact (\%BIC): The contact between the bone-calcified tissue and implant surface is expressed as the BIC percentage according to the total implant surface between two threads (Figure 2).

3. Bone fill percentage $(\% \mathrm{Bf})$ : This is the calcified tissue percentage in the BAFO interspersed by vascular and marrow spaces.

4. Lamellar bone (LB): This bone tissue type exhibits osteonal organization and is measured according to lamellar apposition (Figure 2).

5. Fibroreticular or woven bone (WB): This bone tissue type has a regular bone structure with isolated and polygonal cellular spaces (Figure 2).

6. Calcified chondroid tissue (ChT): This bone tissue type presents a characteristic aspect of calcified tissues with large, irregular, and confluent cellular spaces (Figure 2).

7. Vascular or medullar spaces: black spaces in the BAFO close to the calcified tissue compatible with spaces occupied by blood vessels or bone marrow (Figure 2).

In accordance with the variables described above, we performed quantitative valuation and qualitative analysis. Quantification of tissue areas was performed using the software ImageJ. The SPSS statistical software was used for the analysis of the quantitative results. The ANOVA or Kruskal-Wallis tests were applied and the $p$-value $<0.05$ was considered significant. 


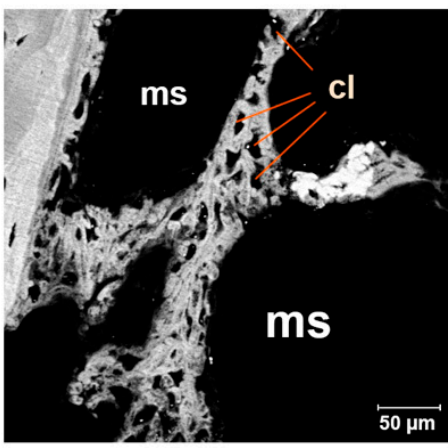

Chondroid tissue

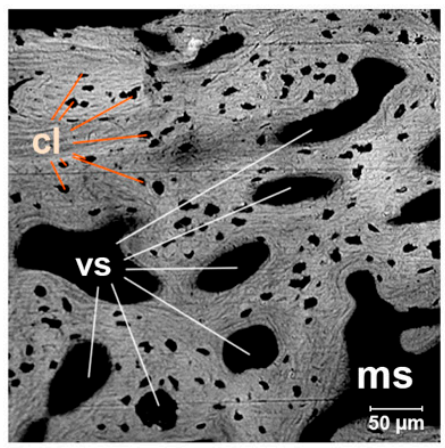

Fibroreticular or woven bone

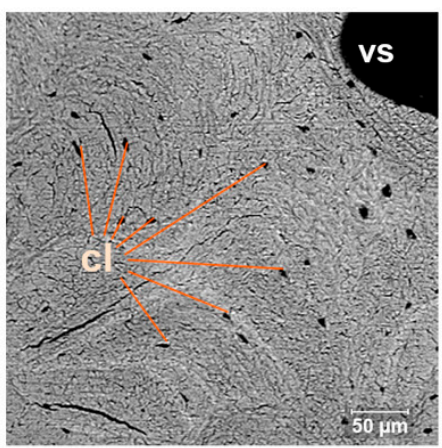

Lamellar Bone

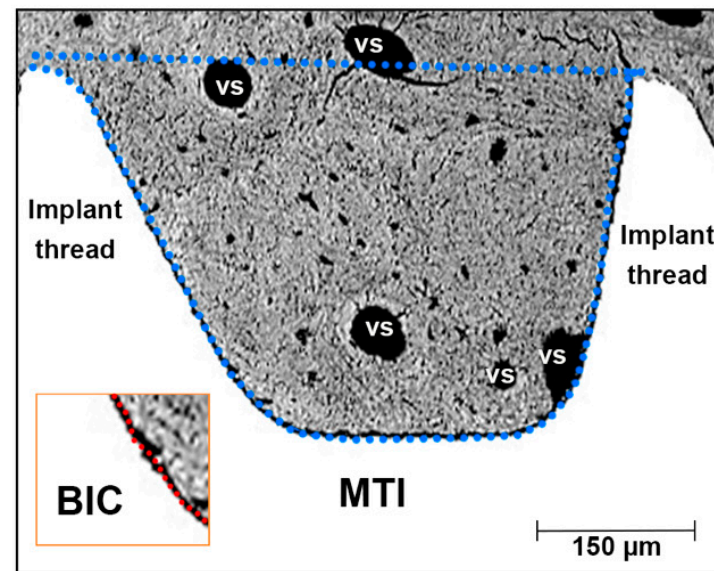

BAFO

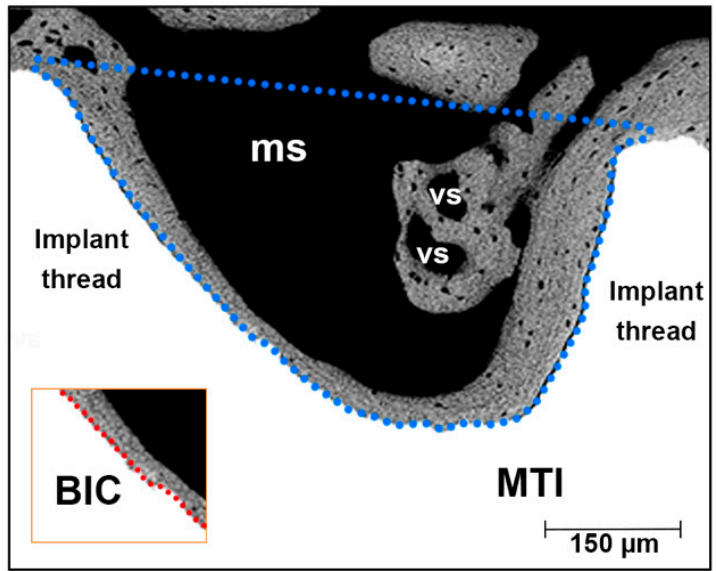

BAFO

Figure 2. In the upper part, the types of bone tissue studied in the samples are shown; in the lower part, the bone area fraction occupancy (BAFO) used as an analysis unit in this study is shown (delimited by the blue broken line between two implant threads). Samples of Bone to Implant Contact (BIC) area are shown in the boxes inside the inferior images. $\mathrm{cl}=$ cellular lacunae; $\mathrm{ms}=$ medullar space; $\mathrm{vs}=$ vascular space; $\mathrm{MTI}=$ mini transitional implant (surface).

\section{Results}

\subsection{General Aspects}

No complications were observed or related by patients in the post-operative period. No mobility or lost implants were observed. A sample was lost during cutting and preparation for BS-SEM analysis. Consequently, 15 samples were studied.

\subsection{Histomorphology Findings}

The histology of the tissue found around the MTIs (BAFOs) obtained by BS-SEM is summarized in Tables 1 and 2 and Figures 3 and 4 . In general, in the space between the MTI surface and trephine, we observed tissue with the characteristics of cortical bone close to the cervical area (near to the implant abutment, Figure 3(1,3). More trabecular bone was observed in the deep area (Figure 3(2,4)). A total of 306 BAFOs were observed, of which 243 BAFOs with calcified tissue were studied. The BAFOs without calcified tissue (63 BAFOs) were observed mainly in relation to the middle implant portion. The samples showed a predominance of trabecular bone. However, the highest BIC percentage considering all samples was associated with cortical bone. Table 1 shows the quantitative observations made in the samples considering the parameters of bone tissue characteristics, bone fill percentages, and BIC. Lamellar bone was the tissue most frequently observed, followed by woven bone. Regions with chondroid tissue were significantly less frequent (Table 2, Figure 4). Even when significant differences were observed in the amount of 
calcified tissue and vascular spaces between the samples, no significant differences were observed in the quantitative analysis considering lamellar, woven, and chondroid tissue (Figure 4). Consequently, the qualitative analysis revealed that the newly formed tissue in the BAFO had a regular cell distribution and characteristics of advanced maturation. In this region, several vascular spaces were observed with surrounding lamellar bone formation. In general, bone exhibited a tendency toward the mature osseous tissue. Besides, no remains of metal or particle corrosion detachment were observed by BS-SEM in the interface BIC or BAFO. Remodeled activity was observed, presumably depending on the forces applied to the implant.

Table 1. Summary of quantitative analysis of bone tissue observed in the BAFOs (Total samples = 15). For BAFO, \%Bf, and \%BIC definitions see the methodology segment. $\mathrm{SD}=$ standard deviation.

\begin{tabular}{cccc}
\hline Bone Tissue & $\begin{array}{c}\text { Number of BAFOs Analyzed } \\
\text { (Total: 306) }\end{array}$ & \%Bf in BAFO & \%BIC (Total) \\
\hline Mainly filled with cortical bone & 94 & $\begin{array}{c}37 \% \text { to } 100 \% \\
(\text { mean } 62 \% \text { SD 15.65) } \\
\text { 24\% to 73\% }\end{array}$ & $63 \%$ \\
Mainly filled with trabecular bone & 149 & $($ mean $44 \%$ SD 14.01) & $37 \%$ \\
Without calcified tissue & 63 & - & - \\
\hline
\end{tabular}

Table 2. Summary of quantitative analysis of samples considering bone tissue types. BAFOs with calcified tissues were considered $(\mathrm{N}=243)$. $\mathrm{SD}=$ standard deviation.

\begin{tabular}{cc}
\hline Bone Tissue Types & Mean \% (SD) \\
\hline Lamellar bone (\% of calcified tissues in BAFOs) & $72.13 \%(13.58)$ \\
Woven bone (\% of calcified tissues in BAFOs) & $26.04 \%(12.39)$ \\
Chondroid bone (\% of calcified tissues in BAFOs) & $1.82 \%(3.69)$ \\
Medullar and vascular spaces (considering all BAFOs area) & $39.41 \%(15.98)$ \\
\hline
\end{tabular}

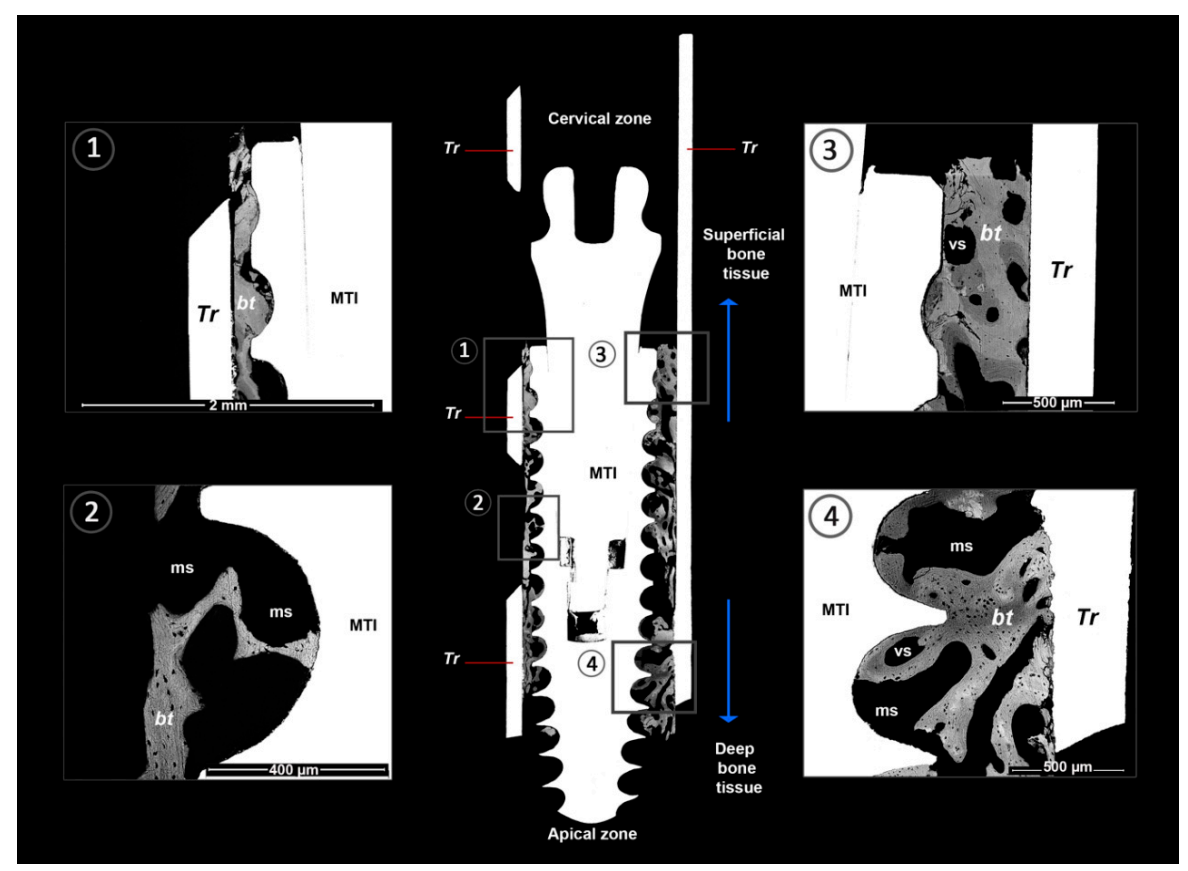

Figure 3. BS-SEM osseointegration between grade V titanium mini-transitional implants (MTI) and the bone surface. The BS-SEM image shows close contact between the implant surface and bone. Furthermore, bone tissue with an advanced degree of maturation and mainly lamellar and fibroreticular tissue organization is observed overall. The subfigures 1-4 show details of the BAFOs in the central image. MTI = mini transitional implant, Facility ${ }^{\circledR} ; \mathrm{Tr}=$ trephine; bt = bone tissue; $\mathrm{ms}=$ medullar space; $\mathrm{vs}=$ vascular space. 


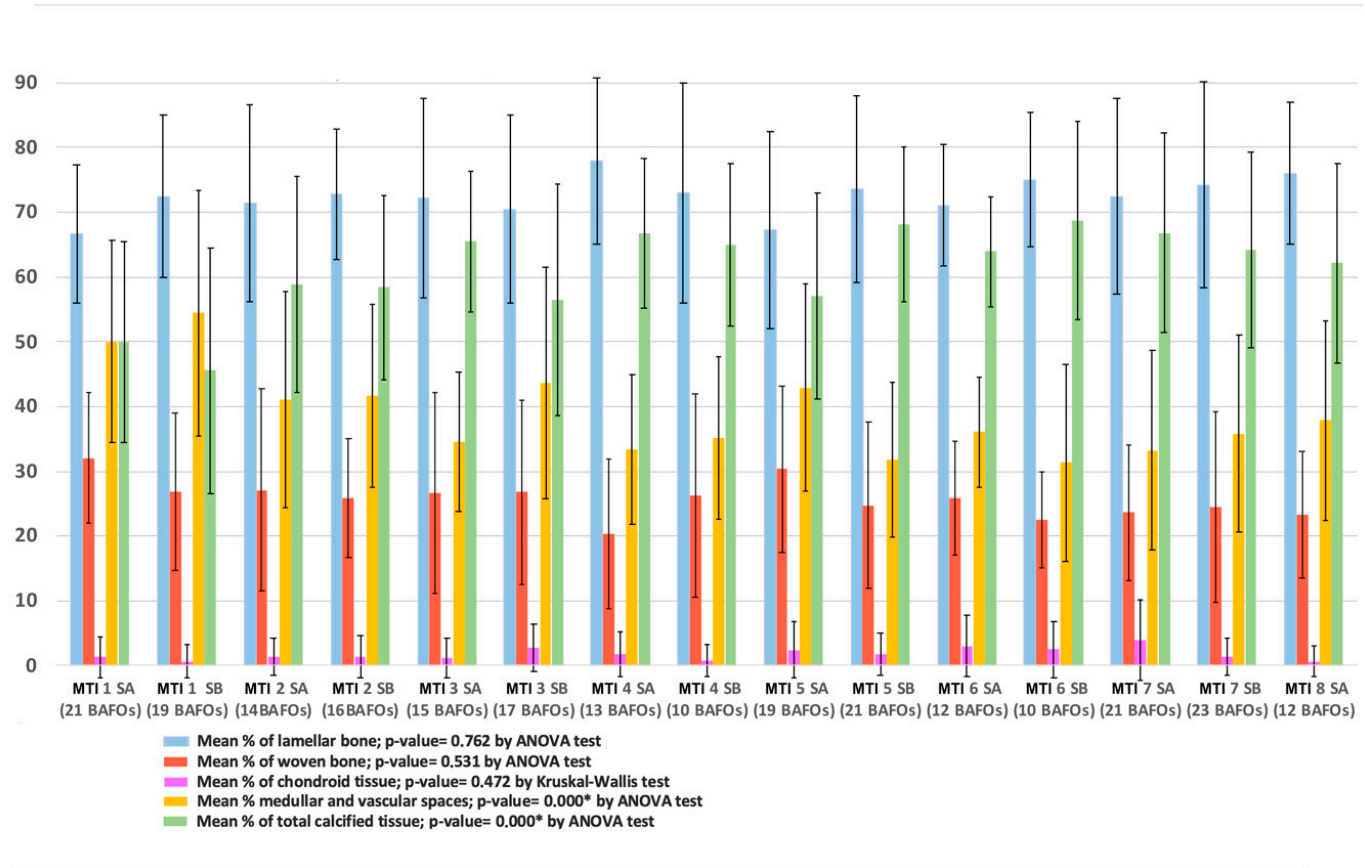

Figure 4. Distribution of calcified tissue considering each sample. MIT = mini transitional implant; SA and SB = Segment A and Segment B of sample (see Figure 1). The number of BAFOs analyzed is described below each set of bars belonging to a sample. No significant differences were observed in the distribution of the types of bone tissue. ${ }^{*}$ Significant differences were observed in the distribution of vascular spaces and general calcified tissue between the samples.

\section{Discussion}

The results of the osseointegration process associated with MTIs placed in the anterior region of the mandible and immediately loaded by overdenture in humans show unprecedent evidence of the successful osseointegration of grade $\mathrm{V}$ titanium in the form of MTIs. The bone quality analyzed in the BAFOs showed characteristics of vascularized mature bone, with minimal evidence of bone in the resorption stage. This result is in agreement with the published histological findings in which the biocompatible and osteoconductive properties of substrate grade $\mathrm{V}$ titanium alloys were evidenced through in vivo studies $[6,7,19]$.

The qualitative evaluation of histology indicated intimate contact between the bone and implant surface, especially in relation to cortical bone (Table 1). Bone formation around MTIs showed healing in the BAFO by an intramembranous-type bone healing pattern, and the appositional formation of new bone was observed where direct contact existed between the implant and bone immediately after placement. These findings are consistent with those described by Granato et al. [20], who observed BAFOs with woven bone appearing with a random orientation at 3 weeks, followed by the remodeling and replacement of woven bone by mature lamellar bone at 6 weeks.

The deposition of the bone matrix around the implant determines the success of the matrix, which depends directly on the process that induces the osteoblast proliferation, differentiation, secretion of extracellular matrix proteins, and tissue mineralization [21]. Along with the above, osseointegration is a dynamic process which alternates between bone formation and bone resorption. Consequently, the magnitude, direction, and period of any forces applied over the implant-bone zone will determine whether maintenance or failure of osseointegration equilibrium results [22]. The results presented here show that the properties of titanium V MTIs plus the correct surgical procedure for implant placement 
achieved adequate stability, allowing a successful osseointegration process, even when an immediate load was applied through an overdenture. It is logical that osseointegration may be influenced by the biomechanical properties, surface texture, and chemical composition of dental implants [23]. Thus, the implant surface (Neoporos) may be a factor that could improve implant success. Castro et al. [24] stated that the Neoporos process is a subtractive surface treatment consisting of zirconium oxide blasting and a series of acid etching baths. Currently, roughened surfaces have been used to increase the total surface area available for osteoconductive process, which could improve bone formation around the implants [25]. Consequently, subtractive treatment of surface and implant design have been considered critical variables that affect stability and quick osseointegration of immediately loaded implants. The above, without consideration of the additive treatment applying bioactive layers on the dental titanium surface, like those performed to improve bone regeneration around degradable temporary orthopedic implants [26]. However, the potential use of additive treatments on temporary implants destined to immediate load should be considered because the advances reported have shown promising results regarding the osseointegration in early stage, the quantity of bone to implant contact, and the adhesion strength of bone-to-implant [27]. Moreover, additive treatment by biodegradable bioactive nanofilms with a sub-micrometric thickness could improve the implant surface without affecting the primary stability required during its insertion. The nanofilms can promote cell proliferation and differentiation, and play a significant role in the matrix calcification [28].

The mechanical resistance of grade $V$ titanium ensures the load transmission to the bone tissue over a prolonged period of time, which is important when lost hard tissues are replaced with a prosthesis [29]. Therefore, the use of alloys with improved mechanical properties in orthopedics and also in implantology is important, especially considering the increasing use and validation of short [30] and small-diameter implants [3] as well as the greater longevity of the patient population [6]. Compared with $\mathrm{Co}-\mathrm{Cr}-\mathrm{Mo}$ alloys, titanium alloy is almost twice as strong and has half the elastic modulus. Compared with $316 \mathrm{~L}$ stainless steel, grade $\mathrm{V}$ titanium alloy is roughly equal in strength; however, it has half the modulus. This titanium alloy is a material that is frequently used in the orthopedic area [21] mainly because of its superior mechanical properties.

Finally, the clinician must consider several aspects for implant selection, such as patient history (parafunctional habits, implant fracture, among others) or load conditions to which the implant will be subjected [31]. The use of titanium grade V in MTIs for immediate prosthetic loading has shown good biomechanical properties and successful osseointegration, maintaining a functional temporary overdenture during the study period.

\section{Conclusions}

Grade V titanium is an adequate material for dental implants from the point of view of its biocompatibility when considering the osseointegration process. Furthermore, the visualization of bone tissue after the removal of MTIs implants with trephine through histomorphometric analysis by BS-SEM demonstrated the presence of mature bone tissue that was mostly formed by lamellar bone. This adequate quality of bone tissue surrounding the dental implant and the intimate and stable contact between the implant surface and bone tissue revealed that, despite the immediate occlusal load applied to the implant, titanium V MTI was adequately integrated into the bone tissue, ensuring the stability of the temporary prosthesis.

Author Contributions: Conceptualization: V.B. and R.L. Research, methodology and supervision: V.B., R.L., B.W. and I.V.-G.; Validation: V.B., R.L., and I.V.-G.; Original draft: V.B., I.V.-G., R.L., C.S., N.F., P.A.-M., and M.-C.M.; Image and photo work: I.V.-G., P.A.-M.; Composition: V.B., I.V.-G., R.L., C.S., N.F., P.A.-M., B.W. and M.-C.M.; Writing, review and editing: V.B., I.V.-G., R.L., C.S., N.F., P.A.-M., B.W. and M.-C.M. All authors have read and agreed to the published version of the manuscript.

Funding: This research was funded in part by MINEDUC-UA project, code ANT 1855, and Insertion Program DI16-6009, Universidad de La Frontera. 
Acknowledgments: We acknowledge ILAPEO (Curitiba, Brazil) for their support of the implants. We also appreciate the collaboration of the Implant Clinic of the School of Dentistry, Universidad Mayor, Santiago, Chile.

Conflicts of Interest: The authors declare no conflict of interest.

\section{References}

1. Mundt, T.; Schwahn, C.; Stark, T.; Biffar, R. Clinical response of edentulous people treated with mini dental implants in nine dental practices. Gerodontology 2015, 32, 179-187. [CrossRef] [PubMed]

2. Veltri, M.; Ferrari, M.; Balleri, P. One-year outcome of narrow diameter blasted implants for rehabilitation of maxillas with knife-edge resorption. Clin. Oral Implants Res. 2008, 19, 1069-1073. [CrossRef] [PubMed]

3. Assaf, A.; Saad, M.; Daas, M.; Abdallah, J.; Abdallah, R. Use of narrow-diameter implants in the posterior jaw: A systematic review. Implant Dent. 2015, 24, 294-306. [CrossRef]

4. De Almeida, F.D.; Carvalho, A.C.; Fontes, M.; Pedrosa, A.; Costa, R.; Noleto, J.W.; Mourao, C.F. Radiographic evaluation of marginal bone level around internal-hex implants with switched platform: A clinical case report series. Int. J. Oral Maxillofac. Implants 2011, 26, 587-592. [PubMed]

5. Calvo-Guirado, J.L.; Gómez-Moreno, G.; Aguilar-Salvatierra, A.; Guardia, J.; Delgado-Ruiz, R.A.; Romanos, G.E. Marginal bone loss evaluation around immediate non-occlusal microthreaded implants placed in fresh extraction sockets in the maxilla: A 3-year study. Clin. Oral Implants Res. 2015, 26, 761-767. [CrossRef]

6. Diaz-Sanchez, R.-M.; de-Paz-Carrion, A.; Serrera-Figallo, M.-A.; Torres-Lagares, D.; Barranco, A.; León-Ramos, J.-R.; Gutierrez-Perez, J.-L. In Vitro and In Vivo Study of Titanium Grade IV and Titanium Grade V Implants with Different Surface Treatments. Metals 2020, 10, 449. [CrossRef]

7. Imam, M.; Fraker, A. Titanium Alloys as Implant Materials. In Medical Applications of Titanium and Its Alloys: The Material and Biological Issues; Lemons, J., Brown, S., Eds.; ASTM International: West Conshohocken, PA, USA, 1996; pp. 3-16.

8. Sharan, J.; Lale, S.V.; Koul, V.; Mishra, M.; Kharbanda, O.P. An Overview of Surface Modifications of Titanium and its Alloys for Biomedical Applications. Trends Biomater. Artif. Organs 2015, 29, 176-187.

9. Ribeiro da Silva, J.; Castellano, A.; Malta Barbosa, J.P.; Gil, L.F.; Marin, C.; Granato, R.; Bonfante, E.A.; Tovar, N.; Janal, M.N.; Coelho, P.G. Histomorphological and histomorphometric analyses of grade IV commercially pure titanium and grade V Ti-6Al-4V titanium alloy implant substrates: An in vivo study in dogs. Implant Dent. 2016, 25, 650-655. [CrossRef]

10. Johansson, C.B.; Han, C.H.; Wenneberg, A.; Albrektsson, T. A quantitative comparison of machined commercially pure titanium and titanium-aluminum-vanadium implants in rabbit bone. Int. J. Oral Maxillofac. Implants 1998, 13, 315-321.

11. Han, C.H.; Johansson, C.B.; Wenneberg, A.; Albrektsson, T. Quantitative and qualitative investigations of surface enlarged titanium and titanium alloy implants. Clin. Oral Implants Res. 1998, 9, 1-10. [CrossRef]

12. Saulacic, N.; Bosshardt, D.D.; Bornstein, M.M.; Berner, S.; Buser, D. Bone apposition to a titanium-zirconium alloy implant, as compared to two other titanium-containing implants. Eur. Cells Mater. 2012, 23, 273-286. [CrossRef] [PubMed]

13. Khan, M.A.; Williams, R.L.; Williams, D.F. Conjoint corrosion and wear in titanium alloys. Biomaterials 1999, $20,765-772$. [CrossRef]

14. Pennekamp, P.H.; Gessmann, J.; Diedrich, O.; Burian, B.; Wimmer, M.A.; Frauchiger, V.M.; Kraft, C.N. Short-term microvascular response of striated muscle to cp-Ti, Ti-6Al-4V, and Ti-6Al-7Nb. J. Orthopaedic Res. Off. Publ. Orthopaedic Res. Soc. 2006, 24, 531-540. [CrossRef] [PubMed]

15. Manzanares, M.C.; Franch, J.; Carvalho, P.; Belmonte, A.M.; Tusell, J.; Franch, B.; Fernandez, J.M.; Cleries, L.; Morenza, J.L. BS-SEM evaluation of the tissular interactions between cortical bone and calcium-phosphate covered titanium implants. Bull. Group Int. Rech. Sci. Stomatol. Odontol. 2001, 43, 100-108. [PubMed]

16. Schnitman, P.A.; Wohrle, P.S.; Rubenstein, J.E. Immediate fixed interim prostheses supported by two-stage threaded implants: Methodology and results. J. Oral Implantol. 1990, 16, 96-105. [PubMed]

17. Manzanares, M.C.; Calero, M.I.; Franch, J.; Jiménez, M.P.; Serra, I. Optimisation of a scheduled study for undecalcified samples. Microsc. Anal. 1997, 50, 17-19.

18. Franch, J.; Pastor, J.; Franch, B.; Durall, I.; Manzanares, M.C. Back-scattered electron imaging of a non-vertebral case of hypervitaminosis A in a cat. J. Feline Med. Surg. 2000, 2, 49-56. [CrossRef]

19. Castellano, A.; Gil, L.F.; Bonfante, E.A.; Tovar, N.; Neiva, R.; Janal, M.N.; Coelho, P.G. Early healing evaluation of commercially pure titanium and Ti-6Al-4V presenting similar surface texture: An in vivo study. Implant Dent. 2017, 26, 338-344. [CrossRef]

20. Granato, R.; Bonfante, E.; Castellano, A.; Khan, R.; Jimbo, R.; Marin, C.; Morsi, S.; Witek, L.; Coelho, P.G. Osteointegrative and microgeometric comparison between micro-blasted and alumina blasting/acid etching on grade III and V titanium alloys (Ti-6Al-4V). J. Mech. Behav. Biomed. Mater. 2019, 97, 288-295. [CrossRef]

21. Zhang, H.; Lewis, C.G.; Aronow, M.S.; Gronowicz, G.A. The effects of patient age on human osteoblasts' response to Ti-6Al-4V implants in vitro. J. Orthop. Res. 2004, 22, 30-38. [CrossRef]

22. Delgado-Ruiz, R.A.; Calvo-Guirado, J.L.; Romanos, G.E. Effects of occlusal forces on the peri-implant-bone interface stability. Periodontology 2000 2019, 81, 179-193. [CrossRef] [PubMed]

23. Colnot, C.; Romero, D.M.; Huang, S.; Rahman, J.; Currey, J.A.; Nanci, A.; Brunski, J.B.; Helms, J.A. Molecular analysis of healing at a bone-implant interface. J. Dent. Res. 2007, 86, 862-867. [CrossRef] [PubMed] 
24. Castro, D.S.; Araujo, M.A.; Benfatti, C.A.; Araujo Cdos, R.; Piattelli, A.; Perrotti, V.; Lezzi, G. Comparative histological and histomorphometrical evaluation of marginal bone resorption around external hexagon and Morse cone implants: An experimental study in dogs. Implant Dent. 2014, 23, 270-276. [CrossRef] [PubMed]

25. Shi, G.S.; Ren, L.F.; Wang, L.Z.; Lin, H.S.; Wang, S.B.; Tong, Y.Q. $\mathrm{H}_{2} \mathrm{O}_{2} / \mathrm{HCl}$ and heat-treated Ti-6Al-4V stimulates pre-osteoblast proliferation and differentiation. Oral Surg. Oral Med. Oral Pathol. Oral Radiol. Endod. 2009, 108, 368-375. [CrossRef] [PubMed]

26. Li, B.; Gao, P.; Zhang, H.; Guo, Z.; Zheng, Y.; Han, Y. Osteoimmunomodulation, osseointegration, and in vivo mechanical integrity of pure Mg coated with HA nanorod/pore-sealed MgO bilayer. Biomater. Sci. 2018, 6, 3202-3218. [CrossRef]

27. Shi, R.; Hayashi, K.; Ishikawa, K. Rapid Osseointegration Bestowed by Carbonate Apatite Coating of Rough Titanium. Adv. Mater. Interfaces 2020, 7, 2000636. [CrossRef]

28. Vannozzi, L.; Gouveia, P.; Pingue, P.; Canale, C.; Ricotti, L. Novel Ultrathin Films Based on a Blend of PEG-b-PCL and PLLA and Doped with ZnO Nanoparticles. ACS Appl. Mater. Interfaces 2020, 12, 21398-21410. [CrossRef]

29. Bauer, S.; Schmuki, P.; von der Mark, K.; Park, J. Engineering biocompatible im- plant surfaces Part I: Materials and surfaces. Prog. Mater. Sci. 2013, 58, 261-326. [CrossRef]

30. Kotsovilis, S.; Fourmousis, I.; Karoussis, I.K.; Bamia, C. A systematic review and meta-analysis on the effect of implant length on the survival of rough-surface dental implants. J. Periodontol. 2009, 80, 1700-1718. [CrossRef]

31. McCracken, M. Dental Implant Materials: Commercially Pure Titanium and Titanium Alloys. J. Prosthodontics 1999, 8, 40-43. [CrossRef] 